\title{
Surgical Indications for Eye Removal in Enugu, South Eastern Nigeria
}

\author{
BI Eze FMCOphth, FWACS, FICS; FC Maduka-Okafor FMCOphth, FICS; OI Okoye \\ FMCOphth, FICS; O Okoye MBBS \\ Department of Ophthalmology, University of Nigeria Teaching Hospital (UNTH), Enugu, Nigeria
}

\section{SUMMARY}

Objective: To determine the surgical indications for removal of the eye in Enugu in south eastern Nigeria.

Method: Retrospective case series review.

Results: At the University of Nigeria Teaching Hospital Enugu, between $1^{\text {st }}$ January 1994 and $31^{\text {st }}$ December 2003, 106 eyes of 106 patients, comprising $71(67.0 \%)$ males and $35(33.0 \%)$ females, aged 6-72 years (mean 31.8), were removed by evisceration (59; 55.7\%), enucleation $(35 ; 33.0 \%)$, and exenteration $(12 ; 11.3 \%)$. Severe open globe injury (49; $46.2 \%)$, infection $(29 ; 27.4 \%)$, malignant tumour (15; $14.2 \%)$ and blind painful eye $(14 ; 13.2 \%)$ were the indications for eye removal. Eye removal was more frequent in males $(67.0 \%)$, among farmers $(21.7 \%)$, and among the 21-40 year age group (41.5\%). Patients who had their eyes removed constituted $0.42 \%$ of new outpatients, $4.63 \%$ of inpatients and $7.83 \%$ of patients who had eye operations during the study period.

Conclusion: The indications for eye removal were mainly for preventable/curable causes. There is, therefore, a need to improve promotive, preventive and curative eye care delivery to reverse this trend.

Key words: eye, removal, indications, Enugu, Nigeria

\section{INTRODUCTION}

Surgical removal of the eye (evisceration, enucleation and exenteration) is an age-old surgical procedure in ophthalmic practice usually embarked on when further retention of the eyeball adversely affects the patient's comfort or jeopardizes his survival. It is a landmark management decision whose effect is usually psychologically and cosmetically devastating to the patient.

Evisceration is the surgical removal of the content of the eyeball while maintaining an intact scleral shell attached to the extraocular muscles. It is absolutely indicated in panophthalmitis to eliminate the risk of retrograde spread of infected orbital contents via the sub-arachnoid space accompanying the optic nerve in the orbit, should other methods of removing the eye be considered. Evisceration is relatively indicated in severe open globe injury, painful blind eye of benign etiology, endophthalmitis unresponsive to medical therapy, and anterior staphyloma ${ }^{1-4}$

Enucleation is the removal of the globe from the orbit, involving the separation of all the connections between the globe and the patient, i.e. extraocular muscles, optic nerve and orbital soft tissues. ${ }^{4}$ This procedure is absolutely indicated in primary intraocular malignancy without evidence of extrascleral spread, phthisis bulbi and micro-ophthalmia. Enucleation and evisceration have similar relative indications. ${ }^{5-10}$ The surgeon's choice between evisceration and enucleation when a relative indication applies is based on the consideration of the risk of post-operative sympathetic ophthalmitis which is, at present, controversial; post-operative implant infection; operative distortion of the orbital anatomy with implications for implant stability; and the risk of postenucleation socket syndrome. ${ }^{8-11}$ However, under this setting, another school of thought advocates leaving the choice of procedure to an informed patient or guardian. ${ }^{10}$

Exenteration is the removal of the globe including all (total exenteration) or part (partial or modified exenteration) of the orbital soft tissues ${ }^{4}$ Traditionally, exenteration is reserved for malignant orbito-ocular neoplasms, however, a benign dimension has recently been added to the indications in conditions such as diffuse idiopathic orbital inflammatory disease leading to irretrievable visual loss, uncontrollable pain and disfigurement; grossly disfiguring orbital abnormalities like teratomas and varices; benign orbital tumours with malignant potential or diffuse orbital infiltration and severe fungal orbital infections refractory to conservative therapy., ${ }^{4,12}$

The standard indications for removal of the eye remain unchanged worldwide, but the primary pathologic conditions necessitating this vary from place to place and are reflective of the ocular morbidity pattern in a given environment. ${ }^{1,2,3}$

${ }^{*}$ Correspondence: Dr B I Eze, Department of Ophthalmology, University of Nigeria Teaching Hospital (UNTH), PMB 01129, Enugu, Nigeria 
Differences in therapeutic development and the socioeconomic environment between developed and developing countries affect the pattern of causes, course and outcome of ocular diseases. Since the indications for eye removal are usually documented and available, this study will elucidate the relative contributions of the various preventable/curable and non-preventable aetiologic factors in a given locality and assist the government and eye care planners in allocating available resources to exert maximal public eye health impact through promotive, preventive, curative and rehabilitative eye care delivery. ${ }^{13}$

Consequently, this study aims at determining the surgical indications for eye removal in our local environment, with emphasis on the primary pathology rather than the immediate or secondary indication for removal of the eye. This will generate data for geographic comparison and public health use.

\section{MATERIALS AND METHODS}

This is a retrospective case series review of all surgical eye removal (evisceration, enucleation and exenteration) done at the Ophthalmology Unit of the University of Nigeria Teaching Hospital Enugu between $1^{\text {st }}$ January 1994 and $31^{\text {st }}$ December 2003.

Data extracted from the patient case notes include: age, sex, occupation, primary ocular diagnosis, method of eye removal, and histology reports.

Records of eye clinic new patient attendance, eye ward admissions, and eye operations during the study period were also obtained and analysed.

Data was analysed using the statistical package for social sciences (SPSS) computer software to generate simple frequency distribution tables and percentages.

\section{RESULTS}

All the case notes relevant to this study were retrieved and analysed. A total of 106 eyes of 106 patients were removed by evisceration $(n=59 ; 55.7 \%)$, enucleation $(n=35 ; 33.0 \%)$ and exenteration $(n=15 ; 14.2 \%)$ during the period under review.

The age and sex distribution of the patients whose eyes were removed is shown in table 1 . The peak age group was 21 - 40 years $(41.5 \%)$. There were more males $(n=71 ; 67.0 \%)$ than females $(n=35 ; 33.0 \%)$; giving a male to female ratio of $2: 1$.

Occupational distribution showed farmers recording the highest $(n=23 ; 21.7 \%)$ and civil servants the least $(n=10 ; 9.4 \%)$ incidence of eye removal (table 2).

An analysis of indications for eye removal showed that open globe injuries accounted for 49 (46.2\%), infections 29 $(27.4 \%)$, malignant tumours $15(14.2 \%)$ and blind painful eye $14(13.2 \%)$ cases (table 3$)$.
Of the 49 traumatic cases, there were 30 (61.2\%) irreparable corneoscleral lacerations, 15 (30.6\%) globe perforations and $4(8.2 \%)$ traumatic limbal rupture with extrusion of intraocular contents.

Table 1. Age and sex distribution of patients

\begin{tabular}{lrrrr}
\hline \multirow{2}{*}{$\begin{array}{c}\text { Age range } \\
\text { (yrs) }\end{array}$} & \multicolumn{2}{c}{ Sex } & No. & $\%$ \\
\cline { 2 - 4 } 0 & $\mathrm{M}$ & $\mathrm{F}$ & & \\
\hline $0-10$ & 8 & 4 & 12 & 11.32 \\
$11-20$ & 4 & 2 & 6 & 5.66 \\
$21-30$ & 16 & 8 & 24 & 22.64 \\
$31-40$ & 13 & 7 & 20 & 18.87 \\
$41-50$ & 9 & 5 & 14 & 13.21 \\
$51-60$ & 8 & 6 & 14 & 13.21 \\
$>60$ & 13 & 3 & 16 & 15.09 \\
\hline Total & 71 & 35 & 106 & 100.00 \\
\hline
\end{tabular}

Table 2. Occupational distribution of patients

\begin{tabular}{lcc}
\hline Occupation & No. & $\%$ \\
\hline Unemployed/minor & 36 & 33.96 \\
Farming & 23 & 21.69 \\
Student & 19 & 17.92 \\
Trading & 18 & 16.98 \\
Civil service & 10 & 9.43 \\
\hline Total & 106 & 100.0 \\
\hline
\end{tabular}

Table 3. Primary ocular diagnosis

\begin{tabular}{lcc}
\hline Diagnosis & No. & $\%$ \\
\hline Trauma & 49 & 46.22 \\
Infection (panophthalmitis) & 29 & 27.36 \\
Tumour & 15 & 14.15 \\
Blind painful eye & 14 & 13.20 \\
\hline Total & 106 & 100.0 \\
\hline
\end{tabular}

Eye trauma was caused by assault $(n=12 ; 24.5 \%)$, road traffic accident $(n=3 ; 6.1 \%)$, fall from height $(1 ; 2.0 \%)$, gunshot injury ( $n=12 ; 24.5 \%)$ and agricultural injury $(n=21 ; 42.9 \%)$.

The 15 eyes that had tumour-related removal break down as follows: 12 were due to retinoblastoma, 2 to squamous cell carcinoma of the conjunctiva and 1 to ocular invasion by maxillary sinus carcinoma.

During the study period, patients who had eye removal constituted $106 / 25,731(0.41 \%)$ of the total new out-patients, $106 / 2,289(4.63 \%)$ of eye ward admissions and 10/1,352 (7.83\%) of eye operations respectively. 
More females $(n=14,141 ; 55.0 \%)$ were seen at the outpatient clinic than males $(\mathrm{n}=11,590 ; 45.0 \%)$, while more males $(n=1,153: 66.1 \%)$ than females $(n=776 ; 33.9 \%)$ were admitted during the same period. The male to female ratio for new outpatients was 1:1.2 and eye ward admission 1.95:1.

\section{DISCUSSION}

The ophthalmology clinic of the University of Nigeria Teaching Hospital is a tertiary eye care facility, located in Enugu, the capital of the former Eastern Region of Nigeria. It takes referrals mainly from the five component states of the South East geopolitical zone. Compared with similar studies, the sample size is small. ${ }^{1-3,14,15,16}$ This is accounted for by the high number of private and public eye care facilities that offer similar surgical services in the South East geopolitical zone, the improved socio-economic conditions of its urban population and the reluctance of patients, who are mainly of Ibo ethnic extraction, to accept eye removal as a treatment option based on socio-cultural beliefs and attitudes.

The socio-demographic profile of patients showed a preponderance of males, with a male to female ratio of 2:1. This agrees with results obtained in Uganda, Jerusalem, Gambia and southwestern Nigeria. ${ }^{1,2,3,14}$ This sex ratio is at variance with the outpatient attendance sex ratio of $1: 1.2$, but is in accordance with the sex ratio of eye ward admissions 1.95:1. Women presenting with minor ocular complaints in the outpatient clinic due to cosmetic concerns, and the engagement of men in high risk activities and occupations that jeopardize eye health, explain these findings. The majority of our patients are in the 21-40 years age group. This is the active age group where trauma- related eye injury occurs more frequently. ${ }^{1,3}$ The incidence of eye removal was highest amongst farmers, obviously due to engagement in injuryprone agricultural activities. In addition, they are domiciled in remote areas, and many encounter transportation and referral problems. They thus present late, after secondary infection has set in and the eyeball is damaged beyond salvage. ${ }^{14,17}$

Aetiologic Factors: We analysed the primary pathology / cause which has been established to be more important than the secondary or immediate cause of eye removal, i.e., the condition of the eye just before removal. ${ }^{2,6}$

Trauma: Severe open globe injury was the leading cause of eye removal accounting for $49(46.22 \%)$ cases. The dominant aetiologic role of trauma in the causation of eye removal has been variously reported. ${ }^{1-3,7,15,16}$ Assault, road traffic accidents and agricultural injuries were the common causes of eye trauma.

The prominence of assault-related ocular trauma in the absence of civil strife is unusual, but the frequent occurrence of armed robbery attacks, cult violence and assassination attempts explain this unusual scenario. Similar to Nwosu's observation, most of the trauma cases were complicated by secondary bacterial infection prior to presentation. ${ }^{17}$ This finding is similar to Davenger ${ }^{1}$ and Olurin's ${ }^{3}$ series but differed from the study by Batten, ${ }^{2}$ Dawodu and Faal, ${ }^{14}$ which had trauma as the third and fourth causes of eye removal.

Infection: This came second to trauma as the causation of eye removal, accounting for $29(27.36 \%)$ cases. At presentation, all the infective cases were at the stage of panophthalmitis, when the chances of restoring vision or retaining the eyeball were foreclosed. The role of primary corneal pathology, like infective corneal ulceration, was difficult to ascertain at this stage due to late presentation. However, a specific history of preceding ocular trauma was ruled out in all cases of primary infection. Olurin ${ }^{3}$ Chaudry et al., ${ }^{8}$ Baiyeroju-Agbeja ${ }^{19}$ and Ukponmwan $^{20}$ reported similar findings, but Batten ${ }^{2}$ and Dawodu and Faal ${ }^{14}$ found that infection was the commonest cause of eye removal. Infection is a major cause of eye removal in developing countries as against developed countries where tumour and blind painful eyes dominate. This can be attributed to advanced eye care services and enhanced ${ }_{23}$ socioeconomic environment in the developed countries. ${ }^{18,21,22,}$

Tumours: Histologically-proven primary malignant orbitoocular neoplasm or extension from maxillary sinus carcinoma caused eyeball removal in $14.2 \%$ of eyes. Retinoblastoma was the commonest neoplasm. This agrees with previous studies by Davenger, ${ }^{1}$ Batten $^{2}$ and Olurin, ${ }^{3}$ but differs from the findings of Dawodu and Faal ${ }^{14}$, Majekodunmi, ${ }^{24}$ Gunalp et al., ${ }^{25}$ Bekibele and Oluwasola, ${ }^{26}$ Ajaiyeoba et al.,${ }^{27}$ and Gassler and Lommatzsch. ${ }^{28}$ Dawodu and Faal ${ }^{14}$ had tumour as the second most common cause of eye removal, while the $\mathrm{Amman}^{18}$ and Majekodunmi ${ }^{24}$ reports had tumour as the topmost cause. The fact that primary intraocular malignancy is more common among Europeans and Asians compared with Africans explains the findings of Amman, ${ }^{18}$ Gunalp et al., ${ }^{25}$ and Gassler and Lommatzsch. ${ }^{28}$ Majekodunmi, ${ }^{24}$ Bekibele and Oluwasola ${ }^{26}$ and Ajaiyeoba ${ }^{27}$ studied post-enucleation specimens where tumour-related indication was high. As previously reported, late presentation, delayed acceptance of surgical treatment, non-availability of alternative treatment modalities such as radiotherapy and laser therapy contributed to the dominance of retinoblastoma. ${ }^{29}$ Malignant uveal melanoma was not a cause for eye removal during the study period. This finding reflects the rarity of the condition in Blacks. $^{21,22,26,27}$

Blind Painful Eye (BPE): This was the reason for eye removal in $13.2 \%$ of the eyes in the present study. Often, the underlying cause was not evident, hence the inclusion in this 
group. This figure is less than Batten's ${ }^{2}(25.53 \%)$, but higher than Davenger's ${ }^{1}(9.18 \%)$, Olurin ${ }^{3}(0.84 \%)$, Vemuganti et al. ${ }^{5}$ $(3 \%)$ and Dawodu and Faal $(5.56 \%) .{ }^{14}$ Batten's series featured many blind painful and disorganized eyes of indeterminate aetiology, justifying their inclusion in this group.

In our study, it was observed that once the diagnosis of $\mathrm{BPE}$ is made, further clinical testing and investigations to establish the underlying cause were abandoned by the patient since these would not affect the outcome of treatment in terms of eye preservation, hence its large proportion. Those patients whose cases were obviously malignant accepted to pay for post-excision histology investigation because of the implications for the fellow eye and survival. Furthermore, alternative treatment of a blind painful eye of benign aetiology, using retrobulbar alcohol and other neurolytic agents, was not a common practice in our centre during the study period. ${ }^{30,31}$

Staphyloma and Phthisis Bulbi: These did not result in any eye removal in our study. This agrees with the findings by Nwosu (staphyloma - 0\%; phthisis bulbi - 0\% ) but differs from reports by Dawodu and Faal ${ }^{14}(81 \%: 10 \%)$, Davenger ${ }^{1}$ $(0 \% ; 2.9 \%)$, Batten $(0 \% ; 14 \%)$ and Olurin ${ }^{3}(0 \% ; 0.42 \%)$. As earlier pointed out, the socio-cultural beliefs of the Ibo - the dominant ethnic group in the catchment area of the study centre-concerning eye removal for cosmetic reasons accounts for this. Among the Ibo, there is a belief that submitting oneself to any ablative surgical procedure, like removal of the eye, would lead to the recurrence of the defect during reincarnation.

Outpatients, Inpatients and Eye Operations: Patients who had surgical operations for eye removal accounted for $0.42 \%$, $4.54 \%$ and $7.83 \%$ of new outpatients, eye ward admissions and eye operations respectively. These figures compare favourably with similar studies previously reported ${ }^{1,2,14}$ but differ from Olurin's findings $(2.8 \%, 16.0 \%, 15.8 \%) .{ }^{14}$ During the period of Olurin's study (1963-1972), ${ }^{3}$ there were fewer private and public secondary and tertiary level eye centres that offered surgical eye care services. Many of the cases were therefore done as outpatient day cases; bed space availability was not a limiting factor during consideration for surgery. This may explain the observed disparity.

\section{CONCLUSION}

Trauma, infection and malignant tumour are the leading causes of eye removal in Enugu. Eye removal is more common in males, and among farmers, and patients aged 2140 years. There is an urgent need for advocacy to stem the trend of eye removal. This should highlight high-risk activities, teach primary first aid for eye trauma and encourage early presentation for specialist care when medical and or surgical treatment alternatives to eye removal are still feasible. In addition, the provision of curative eye care should be made affordable and accessible.

\section{ACKNOWLEDGEMENTS}

We wish to appreciate the secretarial assistance of Gloria Odenigbo and Chinonye Okwuosa during the preparation of this manuscript.

\section{REFERENCES}

1. Davenger M. Causes of enucleation in Uganda. Br J Ophthalmol 1970; 54: 252-255.

2. Batten KL Causes of enucleation as seen in Jerusalem. Br J Ophthalmol 1971; 55: 174-6.

3. Olurin O. Causes of enucleation in Nigeria. Am J Ophthalmol 1973; 73: 987-91.

4. Moshfeghi DM, Moshfeghi AA, Finger PT. Major review: Enucleation. Survey Ophthalmol 2000; 44(4): 277-301.

5. Vemuganti GK, Jalali S, Honavar SG, Shekar GC. Enucleation in a tertiary eye care center in India. Eye 2001; 15(Pt 6): 760-5.

6. Obuchowska I, Mariak Z, Sherkawey N. Clinical indications for enucleation: A review of the literature. Klin Oczna 2005; 1071(13): 159-627.

7. Cheng GY, Li LQ, Gao F, Ren RG, Xu XL, Jonas JB. Review of 1375 enucleations in the Tong Ren Eye Centre. Eye 2007 Jun 29;[Epub ahead of print] :doi:10.1038/sj.eye.6702919 (date accessed:26/07/2007).

8. Chaudry IA, Aikuraya HS, Shansi FS, Elzaridi E, Riley FC. Current indications and resultant complications of evisceration. Ophthalmic Epidemiol 2007; 14(2): 93-7.

9. O'Donnell BA, Kerston R, McNab A, Rose G, Rosser P. Enucleation versus evisceration. Clin Experiment Ophthalmol 2005; 33(1): 5-9.

10. Migliori ME. Enucleation versus evisceration. Curr Opin Ophthalmol 2002; 13(5): 298-302.

11 Bilyk JR. Enucleation, evisceration, and sympathetic ophthalmia. Curr Opin Ophthamol 2000; 11(5): 272-86.

12. Rose GE, Wright JE. Exenteration for benign orbital disease. $\mathrm{Br}$ J Ophthalmol; 78: 14-18.

13. Lee PP, Jackson CA, Relles DA. Estimating eye care work force. Ophthalmology 1995; 73: 987-91.

14. Dawodu AO, Faal HB. Enucleation and evisceration in the Gambia. Nig J Ophthalmol 2000; 8(1): 29-33.

15. Haile M, Alemayehu W. Causes of removal of the eye in Ethiopia. East Afr Med J 1995; 72(11): 735-8.

16. Kaimbo K. Causes of enucleation in Zaire. J Fr Ophthalmol 1998; 11(10): 677-80.

17. Nwosu SN. Destructive ophthalmic surgical procedures in Onitsha, Nigeria. Niger Postgrad Med J 2005; 12(1): 53-6.

18. Amman PB. Data and comments on enucleation of the eye: Studies on patients of the University Eye Clinic Basel, 19301934. Klin Monatsbl Agenheilk 1962; 140: 238-42. 
19. Baiyeroju-Agbeja AM, Ajibode HA. Causes of removal of the eye in Ibadan. Nig J Surg 1996; 3: 33-40.

20. Ukponmwan CU, Enock M. Causes of removal of the eye in Benin City. Nig J Surg (in press).

21. Lim JKS, Cinotti AA. Causes of removal of the eye: a study of 890 eyes. Ann Ophthalmol 1976; 8: 85-9.

22. Degottrau P, Holbach LM, Nauman GO. Clinicopathological review of 1146 enucleations (1980-1990). Br J Ophthalmol 1994; 8: 260-65.

23. Shpiro A, Monselise MB. Destructive ophthalmic surgical procedures, a comparison between a developed and a developing country. Albrecht Von Graefs Arch Klin Exp Ophthalmol 1978; 207(4): 271-3.

24. Majekodunmi S. Causes of enucleation of the eye at Lagos University Teaching Hospital: A study of 101 eyes. West Afr J Med 1989; 8: 288-291.
25. Gunalp I, Gunduz K, Ozkan M. Causes of enucleation: A clinicopathological study. Eur J Ophthalmol 1997; 7(30): 223-8.

26. Bekibele CO, Oluwasola AO. A clinicopathological study of orbito-ocular diseases in Ibadan between 1991-1999. Afr J Med Med Sci 2003; 32(2): 197-202.

27. Ajaiyeoba IA, Pindiga HU, Akang EE. Tumours of the eye and orbit in Ibadan. East Afr Med J 1993; 69(9): 487-9.

28. Gassler N, Lommatzsch PK. Clinicopathologic study of 817 enucleations. Klin Monatsbl Agenheilkd 1995; 5: 295-301.

29. Onwasigwe EN. The practice of exenteration in Nigeria. Orient J Med 2001; 3(3\&4): 46-8.

30. al-Faran MF, al-Omar OM. Retrobulbar alcohol injection in blind painful eyes. Ann Ophthalmol 1990; 22(12): 460-2.

31. Merbs SL. Management of a blind painful eye. Ophthalmol Clin North Am 2006; 19(2): 287-92. 